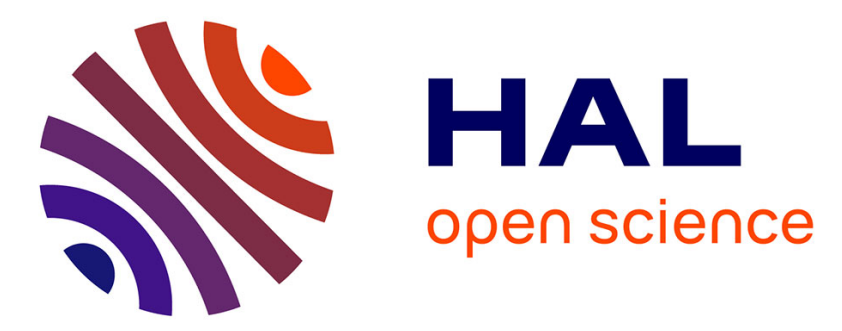

\title{
Hyaluronic Acid - TB Drug Conjugates for the Treatment of Active Tuberculosis Disease
}

Riaz Khan, V. Aroulmoji, C. Sivasankar, M. Deepa

\section{To cite this version:}

Riaz Khan, V. Aroulmoji, C. Sivasankar, M. Deepa. Hyaluronic Acid - TB Drug Conjugates for the Treatment of Active Tuberculosis Disease. International journal of advanced Science and Engineering, 2020, 7 (1), pp.1625-1628. 10.29294/IJASE.7.1.2020.1625-1628 . hal-03107091

\section{HAL Id: hal-03107091 \\ https://hal.science/hal-03107091}

Submitted on 22 Jan 2021

HAL is a multi-disciplinary open access archive for the deposit and dissemination of scientific research documents, whether they are published or not. The documents may come from teaching and research institutions in France or abroad, or from public or private research centers.
L'archive ouverte pluridisciplinaire HAL, est destinée au dépôt et à la diffusion de documents scientifiques de niveau recherche, publiés ou non, émanant des établissements d'enseignement et de recherche français ou étrangers, des laboratoires publics ou privés. 


\title{
Hyaluronic Acid - TB Drug Conjugates for the Treatment of Active Tuberculosis Disease
}

\author{
Riaz Khan'1, V.Aroulmoji², C.Sivasankar ${ }^{3}$, M.Deepa ${ }^{4}$ \\ ${ }^{1}$ Rumsey, Old Bath Road, Sonning, Berkshire, RG4 6TA, England, United Kingdom \\ ${ }^{2}$ Centre for Research \& Development, Mahendra Engineering College (Autonomous), \\ Mallasamudram, Namakkal (Dt.) - 637 503, Tamil Nadu, India \\ ${ }^{3}$ Department of Chemistry, Pondicherry University, R.V.Nagar - 605014, Pondicherry, India \\ ${ }^{4}$ Postgraduate and Research Department of Chemistry, Muthurangam Government Arts College, Vellore, India
}

ABSTRACT: We propose to develop a novel drug conjugate from Hyaluronic acid (HA), a biomaterial ubiquitously present in our body, and Ethambutol and Isoniazid, two promising Mycobacterium (M) Tuberculosis (TB) drugs. Nevertheless, in general, the TB drugs are not only associated with some toxicity but also the patients can develop resistance to the drug. The conjugates of HA and MTB drugs are expected to act synergistically to eliminate those shortcomings.

KEYWORDS: Tuberculosis, Hyaluronic acid, Ethambutol, Isoniazid, drug conjugation

\section{INTRODUCTION}

Evidence of Tuberculosis (TB) caused by Mycobacterium bacteria goes way back to long human history; the earliest written mentions of TB were started in India and in China, 3,300 and 2,300 years ago, respectively. Even today, it is one of the world's seventh-leading diseases causing death and a third disease in infecting people worldwide with Mycobacterium tuberculosis, the bacterium that causes TB. According to the WHO [1], the 30 high TB burden countries accounted for $87 \%$ of all estimated incident cases worldwide, and eight of these countries accounted for two thirds of the global total: India (27\%), China (9\%), Indonesia (8\%), the Philippines (6\%), Pakistan (6\%), Nigeria (4\%), Bangladesh (4\%) and South Africa (3\%).

HIV infected people show further complications because of drug-drug interactions between anti-TB drugs and antiretroviral therapies, and by cumulative drug toxicities that amplify the risk of immune reconstitution inflammatory syndrome.

The WHO global Tuberculosis (TB) report 2019, highlights the following main challenges for the treatment of TB disease: (i) the duration and complexity of the present drug regimens, both of which affect adherence, (ii) toxic side-effects, especially the drugs used for the treatment MDR and XDR TB patients, (iii) the absence or limited availability of pediatric drug formulations for second-line treatment, and (iv), most importantly, there is a pressing need for enhanced efficacy of regimens that are more effective, more affordable, nontoxic, and that shorten the duration of treatment.

There are nearly ten drugs currently approved by the U.S. Food and Drug Administration (FDA) for treating TB disease. Patients with latent tuberculosis may need to take only one or two types of TB drugs. However, patients suffering from active tuberculosis, particularly if it is a drug-resistant strain, will require several drugs at once. The most common medications used to treat tuberculosis include: Isoniazid [2-4], Rifampin [5,6] (Rifadin, Rimactane), Ethambutol (Myambutol) [7,8], and Pyrazinamide [9,10].

Serious side effects of TB drugs aren't common but can be dangerous when they do occur; all tuberculosis medications can be highly toxic to liver. In this regard, based on our previous experience we set our objectives to contribute in the drug discovery for TB. The aim of our research is to develop and register novel hyaluronic acid -TB drug conjugates, especially for the treatment of MTR TB and XTR TB disease with a competitive profile, globally.

Our previous research work on specific conjugation of hyaluronic acid (HA) with pharmacologically active compounds such as camptothecin, methotrexate, methyl prednisolone, and propofol to a number of novel drugs for the treatment of cancer, arthritis,

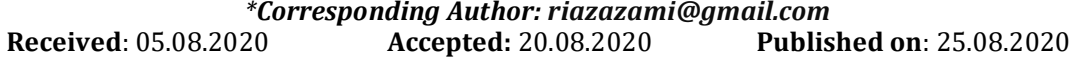

Riaz Khan et al., 
osteoporosis, immune disorder and sedation; the purpose to covalently link the drugs with HA was to deliver the drug in a targeted manner, enhance its solubility, improve its localization, controlled release in the body, eliminate or reduce its toxicity, and enhance its overall efficacy [11-13].

In the organism, HA occurs in many diverse forms, circulating freely, decorated with a variety of HAbinding proteins (hyaladherins), tissue-associated, intercalated into the ECM by electrostatic or covalent interaction to other matrix molecules. It comprises a major portion of the intimate glycocalyx, also known as the pericellular matrix, is a glycoprotein and glycolipid covering that surrounds all cells. In addition to this, it's various biological properties such as biodegradability, biocompatibility, non-toxicity, hydrophilicity, and non-immunogenicity, together with the availability of various functional groups that allow the conjugation of drugs, is extremely valuable in medicine. HA mediates its biological functions through specific protein receptors present on the different cell surface, which include CD44 [14], HARE [15], RHAMM [16], and LYVE [17].

Hyaluronic acid is present in lung tissue and it shields the respiratory organ scleroprotein from inflammation [18]. Scientific evidences confirm that HA is used in the distribution of drugs to the respiratory organ and also its sustained release of drug makes it biocompatible, half-life extension, solubility enhancement, possibility of high drug loading, less toxicity, and increase drug retention time $[11,12,19]$.

It is well recognized that the most promising approaches to targeted drug delivery is nanotechnology; HA with its nano-size dimensions and ability to display a target moiety to ligands, nanodelivery systems can impart drugs more efficiency, more selectivity and more specificity to the treatment of Mycobacterium TB. In addition, Macrophages are known to express HA receptors such as CD44; which is a macrophage-binding site for Mycobacterium TB; with the CD44 receptor on its outer membrane, a macrophage can become a target cell for MTB treatment, using an HA - MTB conjugate modified nano-carrier [20]. It is of surprising to note that hitherto, HA-MTB drug conjugates for the treatment of MTB have not been reported. There is an urgent need to develop an effective drug for active tuberculosis and particularly in the light of the fact that drug resistance TB remains a major concern in many countries.

The hyaluronic acid conjugates with the promising TB drugs, such as Ethambutol [7], Isoniazid [3,4], Rifampin [5], and Pyrazinamide [9,10], will be prepared and their potential as an efficient TB drug will be investigated by conducting in-vitro and in-vivo studies.<smiles>CC[C@H](CO)NCCN[C@H](CC)CO</smiles>

Figure 1 Ethambutol

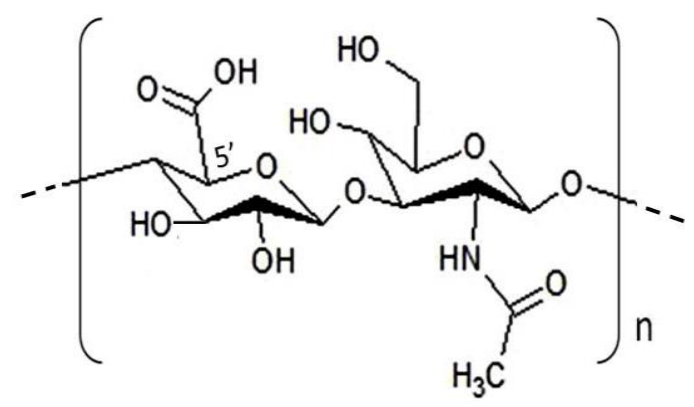

Figure 2 Hyaluronic acid

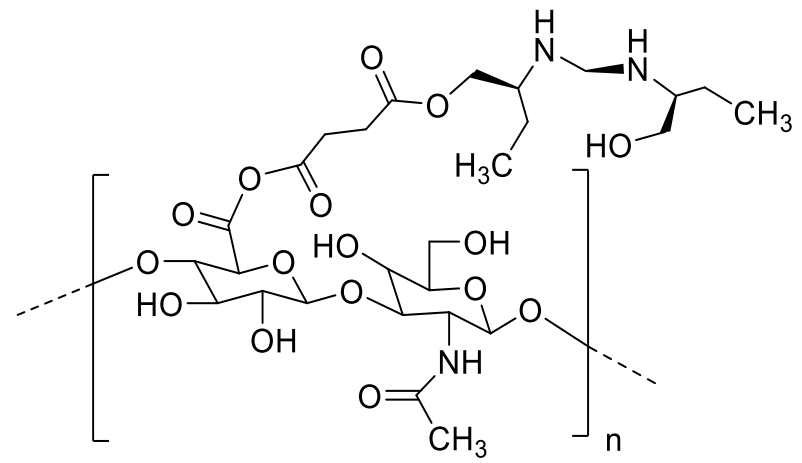

Figure 3 HA- Ethambutol Conjugate

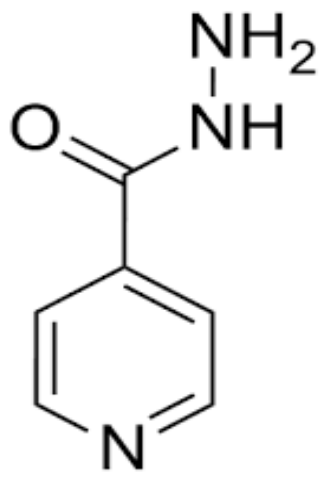

Figure 4 Isoniazid

Riaz Khan et al., 


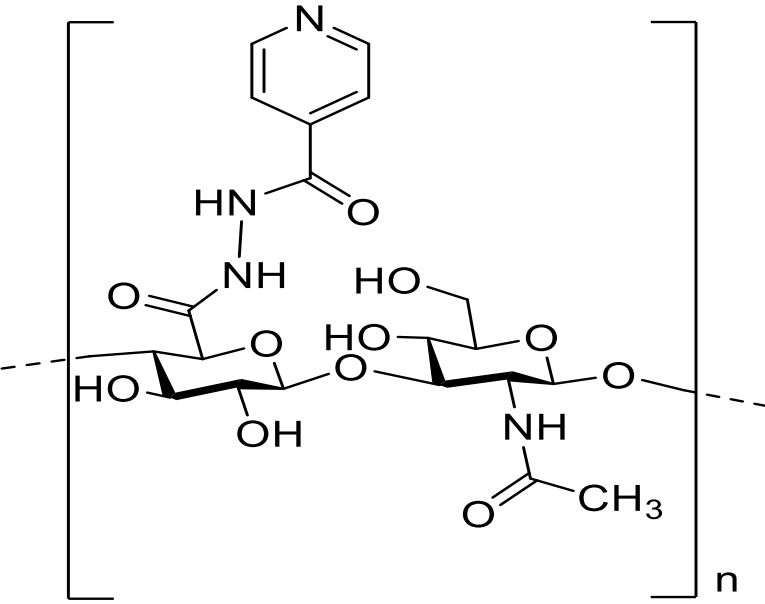

Figure 5 Hyaluronic acid - Isoniazid Conjugate

The conjugation of Ethambutol (Fig.1) to hyaluronic acid (Fig.2) can be achieved through one of its two hydroxyl groups and the C5'carboxylic group of the Dglucuronic acid moiety of the HA, through an ester linkage between the two compounds to afford HAEthambutol conjugate (Fig. 3). For the detail methodology of the proposed strategy, one can refer the patent on the conjugation of methylprednisolone with HA [21].Similarly, Isoniazid (Fig. 4) can be covalently linked through its amino group at the C5'carboxylic group of the D-glucuronic acid moiety of the HA via an amide ester linkage to afford HAIsoniazid conjugate (Fig. 5).

\section{CONCLUSION}

A number of HA-MTB drug conjugates, using different molecular weight of hyaluronic acid and different degree of substitution of the chosen anti-TB drug conjugates, will be prepared and tested for their activity against active tuberculosis.

\section{REFERENCES}

[1] Global tuberculosis report 2019, https://www.who.int/tb/publications/global _report/en/

[2] Daniel, Thomas M, “Captain of Death: The Story of Tuberculosis", University of Rochester Press, 1997

[3] Zumla A, Nahid P, Cole ST. 2013. Advances in the development of new tuberculosis drugs and treatment regimens. Nat Rev Drug Discov 12: 388-404

[4] Vilcheze C, Jacobs WR Jr. 2007. The mechanism of isoniazid killing: Clarity through the scope of genetics. Annu Rev Microbiol 61: 35-50.
[5] Leroy Hyde, 1972. Rifampin in the Treatment of Pulmonary Tuberculosis, Calif Med. 1972 117(6): 18-21.

[6] Boeree MJ, Diacon AH, Dawson R, Narunsky K, du Bois J, Venter A, Patrick P J Phillips, Stephen $\mathrm{H} \quad$ Gillespie, Timothy D McHugh, Michael Hoelscher, Norbert Heinrich, Sunita Rehal, Dick van Soolingen, Jakko van Ingen, Cecile MagisEscurra, David Burger, Georgette Plemper van Balen, Rob E Aarnoutse, PanACEA Consortium, 2015. A dose-ranging trial to optimize the dose of rifampin in the treatment of tuberculosis. Am J Respir Crit Care Med. 191(9):1058-65

[7] Ethambutol for the treatment of tuberculosis, https://www.medicinesforchildren.org.uk/etha mbutol-treatment-tuberculosis

[8] Saggese, Miguel D., Tizard, Ian, Gray, Patricia, Phalen, David N. 2014. Evaluation of Multidrug Therapy with Azithromycin, Rifampin, and Ethambutol for the Treatment of Mycobacterium avium subsp avium in Ring-neck Doves (Streptopeliarisoria): An Uncontrolled Clinical Study, Journal of Avian Medicine and Surgery, 28(4):280-289.

[9] Alice L. den Hertog, Sandra Menting, Richard Pfeltz, Matthew Warns, Salman H. 2016. Siddiqi, Richard M. Anthony, Pyrazinamide Is Active against Mycobacterium tuberculosis Cultures at Neutral pH and Low Temperature, Antimicrobial Agents and Chemotherapy, August, 60 (8) 49564960

[10] Zhang Y, Mitchison D. 2003. The curious characteristics of pyrazinamide: a review. Int J Tuberc Lung Dis 7:6 -21

[11] Sorbi, C., Bergamin, M.,Bosi, S .,Dinon, F., Aroulmoji, V., Khan, R., Murano E.,Norbedo.S. 2009. Synthesis of 6-0 methotrexylhyaluronan as a drug delivery system. Carbohydrate Research, 344, 91-97.

[12] Norbedo, S., Dinon, F., Bergamin, M., Bosi, S., Aroulmoji, V., Khan R., Murano. E. 2009.Synthesis of 3-Deoxy-6-amino-hyaluronan based as an intermediate for conjugation with carboxylate - containing compounds: Application to hyaluronan - camptothecin conjugates. Carbohydrate Research, 344, 98-104

[13] Khan, R., Mahendhiran,B., Aroulmoji,V. 2013. Chemistry of Hyaluronic Acid and Its Significance in Dug Delivery Strategies, International Journal of Pharmaceutical Sciences and Research, 4(10): 3699-3710.

[14] Underhill C, CD44: the hyaluronan receptor, J Cell Sci., Oct 103 (Pt 2):293-288 (1992).

[15] Pandey, MS., Weigel, PH. 2014. Hyaluronic Acid Receptor for Endocytosis (HARE)-mediated Endocytosis of Hyaluronan, Heparin, Dermatan Sulphate, and Acetylated Low Density Lipoprotein (AcLDL), but Not Chondroitin

Riaz Khan et al., 
Sulphate Types A, C, D, or E, Activates NF-кBregulated Gene Expression , J Biol. Chem., Jan 17, 289(3): 1756-1767.

[16] Park, D., Youngmi Kim., Hyunah Kim., Kyungjong Kim., Yun-Sil Lee., Jongseon Choe., Jang-Hee Hahn., Hansoo Lee., Jongwook Jeon., Chulhee Choi Young-Myeong Kim., Dooil Jeoung,2012. Hyaluronic Acid Promotes Angiogenesis by Inducing RHAMM-TGF $\beta$ Receptor Interaction via CD44-PKC 8 , Molecules and Cells, 33, 563-574.

[17] Lawrance, W., Banerji S, Day A. J. Bhattacharjee S., Jackson DG.2016. Binding of Hyaluronan to the Native Lymphatic Vessel Endothelial Receptor LYVE-1 Is Critically Dependent on Receptor Clustering and Hyaluronan Organization. J Biol. Chem. Apr 8, 291(15), 801430.
[18] Konno, K., Arai, H., Motomiya, M., Nagai., Ito, M., Sato, H., Satoh, K, 1982.A biochemical study on glycosaminoglycans (mucopolysaccharides) in emphysematous and in aged lungs, Am Rev Respir Dis, Nov;126(5):797-801.

[19] Arianna Fallacara, Erika Baldini, Stefano Manfredini, Silvia Vertuani, 2018, Hyaluronic Acid in the Third Millennium, Polymers (Basel) Jun 25;10(7):701

[20] Yuan Gao, Muhammad Khan Sarfraz, SophieDorotheeClas, Wilson Roa, Raimar Löbenberg,2015.Hyaluronic Acid-Tocopherol Succinate-Based Self-Assembling Micelles for Targeted Delivery of Rifampicin to Alveolar Macrophages, J. Biomed. Nanotechnol. 11, 13121329.

[21] Khan, R., Konowicz, P. A. 1996. Hyaluronan conjugates with pharmaceutically active substances, methods and compositions. Patent WO 96/35721. 